\title{
DISCUSSION
}

\section{A reassessment of the causes of the Carsington embankment failure}

\author{
P. W. ROWE (1991). Géotechnique 41, No. 3, 395-421
}

\section{A. D. M. Penman, Geotechnical Engineering Con- sultant}

Professor Rowe deserves praise for his thorough and detailed post-failure analysis of Carsington dam. Our profession has gained considerably from all the post-failure investigations. We have learned more about the dangers of pre-existing slip surfaces, left for us in many foundation soils by the geological history of the site, and we have been given analytical methods for assessing progressive failure by Skempton, Vaughan, Potts and others. Now we have an explanation based on slip surfaces formed by placing and compacting machinery during construction of the embankment.

This latest study gives a clear picture of the vital load transfer taking place around the base of the core and the boot at a very early stage during the winter shut-down of 1982-1983 when the pore pressure increased markedly at $\mathrm{C} 1$ and $\mathrm{C} 2$. Fascinating though this study is, one must ask why the boot was there, to cause the trouble it did.

There is an argument that if $\mathbf{G}$. H. Hill had designed the dam as they had designed very many successful dams previously in their long history, Carsington would also have been successful. It was not a high dam and it had the traditional $1: 3$ upstream and $1: 2 \frac{1}{2}$ downstream slopes. If it had also had a vertical, central soft clay core and the thin layer of soft weathered yellow clay had been stripped to provide a firm foundation on the mudstone, it can be shown that it would have been stable. The practising engineer needs an explanation of why the soft yellow clay was not removed and why a slightly sloping core was adopted, with its unusual extended boot which provided a path for an upstream slip surface. The downstream shoulder, with the steeper of the two outer slopes, also standing on the yellow clay, has remained remarkably stable. Horizontal magnet gauges in this shoulder have shown only small movements. It might be inferred that if the upstream batter of the core had been the same as that on the downstream side, it would have imposed a similar horizontal thrust on the upstream shoulder. With its flatter outer slope, the upstream shoulder should have been stable, even though in the early stages of reservoir filling the factor of safety would have reduced. Even on the yellow clay, but without the boot, the dam could have survived. Without the layer of soft yellow clay in the foundation, it should have been quite stable.

All the analyses that have been made relied on the excellent results given by the reliable instrumentation and illustrate clearly the value of correct instrumentation in a dam. It might be asked if the type of analysis of instrumentation readings (including movement measurements) now made post-failure by Professor Rowe could have been made during construction so that the seriousness of the situation could have been made apparent and failure averted, i.e. can instruments give warning of impending failure? The answer unequivocally is yes.

The reason for the berm, placed against the upstream toe to level $176 \mathrm{~m}$ in July 1983, was that a separate stability analysis had shown that the factor of safety could be increased significantly for the 1983 season. Measurements of horizontal movements, giving the evidence shown by Fig. 6, only began in August 1983 to see if the berm was being effective. During the winter shutdown of 1983-1984 sections of five pegs were placed across the top of the clay core and the measured settlements were as shown by Fig. 27. At the same time the cross-arm gauge mentioned by Professor Rowe blocked at level $179 \mathrm{~m}$ and the piezometer CU1 beyond the boot toe failed as though the connection had blocked. These three features pointed to the formation of the slip surface on which, some time later and after the addition of more weight of fill during the early stages of the 1984 season, the failure occurred.

I agree with Professor Rowe that shear failure was occurring in the soil before 4 June 1984. It may be difficult to define what is meant by shear failure in this context, but considering the small strains to failure in laboratory tests of this soil, the strains occurring during the 1983-1984 shutdown and before, which caused the cross-arm blockage and piezometer failure, can have been 

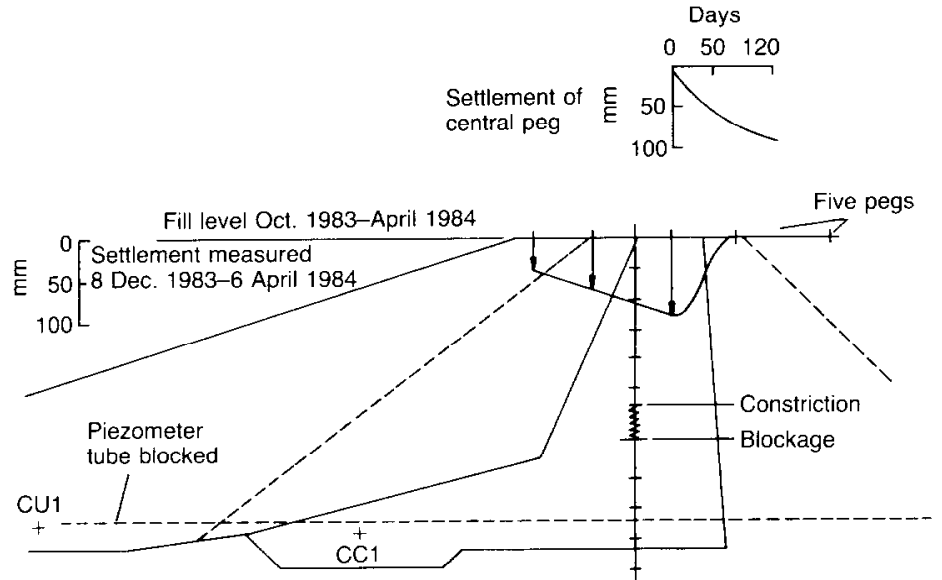

Fig. 27. Conditions at the end of the 1983-1984 winter shut-down, before the beginning of the 1984 placing season

expected to have developed sheared surfaces. But how much warning of failure is required to initiate a design review that would alter the dam section and preserve stability? And what was the real purpose for the large base extension of the core forming the shape that has been described as the boot?

\section{J. Knight, Sir Alexander Gibb \& Partners Ltd}

The Author's splendidly provocative and characteristically highly original paper, in which he has painstakingly reassessed the causes of the Carsington embankment failure has ensured that the original embankment will not even nowdespite its partial burial beneath Carsington 2 -be allowed to lie down. The arguments presented have reinforced my suspicion that some previous explanations of the failure have tended to be more a description of an extended failure process during its progress than an exposition of its causative mechanism(s)

The Author's remarks on the role of 'extensive plant construction shears formed during the critical first season' (p. 396) deserve comment, as do the statements on p. 404 that 'Scarification was not specified ... effective scarification was irregular' and that a smooth-wheeled roller was used on zones I and II. As the Author states on p. 420, 'prior published information relating to plant shears' already existed, examples of which are Pavlakis (1978) and Parsons (1978). The former, for instance, relating to the construction by a (clogged up) tamping foot roller of the clay core $(\mathrm{PI}=17 \%)$ of the Pournari Dam in Greece refers to "smooth horizontal surfaces having the appearance of a slickenside at almost every boundary between layers ... and sometimes many such surfaces within one layer', to which the 'solution applied to the problem was double scarification .... Parsons (1978) concludes that 'special measures may have to be taken to avoid the formation, in critical situations, of discontinuities within or between compacted layers'. Certainly a dam embankment fill would qualify as a 'critical situation".

These examples suggest that the Author's statement (p. 396) that 'there is therefore a new finding of importance in all earthworks, namely that near-continuous shear surfaces ... can be formed by man', requires a little verbal scarification to ensure proper bonding of the important example he gives to past experience. I recall, in connection with the design and construction of the major embankments of the Roseires Dam, Sudan, in the 1960s, the designers' specific concern that there should be no built-in construction-induced shear surfaces in the highly plastic Black Cotton Clay core zone. I also recall that a similar concern was held at this possibility occurring during the construction of Palmar Dam, Uruguay, in the late 1970s. Accordingly I warned of these specific and possible threats to embankment core integrity (Knight, 1989), in the following terms: 'A clay barrier has six requirements, the first being vertical continuity; each layer must be bonded to the one below ..., and 'It is important not to build in local construction defects such as shears caused by the compaction plant ...' as stated in paragraphs 2 and 14 respectively of that reference. These examples and statements, I suggest, demonstrate a different situation to that suggested by the Author on p. 396 that apparently none of those who spoke at meetings on the 
failure ... were aware that construction operations could damage earthworks to the extent they did'.

The Author has provided a valuable case history reassessment of an important geotechnical failure, one of the many lessons from which must be to highlight the essential continuous partnership between the design and construction parties to a major embankment dam, the design of which, as has been said often before, is not complete until its construction is complete. Perhaps the most sobering statement which the Author makes is in his final paragraph on p. 421 , on the possibility that the failure could have occurred during initial impounding. The consequences of that would have been of a different order altogether. Mercifully, the local residents were not so visited.

\section{W. Cox, Polytechnic of Central London}

The difficulty in providing a thoroughly acceptable explanation for the slip at Carsington is that the failed dam slopes were at $18^{\circ}(1: 3)$ while the angle of friction of the fill and underlying soil was typically $20^{\circ}-30^{\circ}$ with some higher values. The piezometers in the fill recorded no significant pore water pressure (outside the core) and a comparison of the angles of friction and slope gives a high factor of safety, especially against deepseated failure.

A second anomaly is that the Carboniferous Coal Measure shale forming the fill and foundation is a widespread deposit and numerous embankments and cuttings have been constructed in essentially the same material, often using the same method (i.e. roller compaction). These embankments stand successfully at slopes typically of $27^{\circ}(1: 2)$ to $22^{\circ}(1: 2 \cdot 5)$ with a negligible number of failures, particularly deep-seated failures. Parsons \& Perry (1985) conducted an extensive examination of $300 \mathrm{~km}$ of motorway embankments. The Coal Measure shale embankments, predominantly at slopes of $27^{\circ}(1: 2)$, were among the most stable of all the various fills used, with only a $2 \%$ failure rate. A slope of $18^{\circ}(1: 3)$ had a predicted failure rate of less than $1 \%$. Coal Measure shale railway embankments (end-tipped without roller compaction) are often found standing at angles up to $35^{\circ}$ or more. Some of the road and rail embankments are as high or higher than Carsington, and many are in poorer unselected material or on much steeper side-long ground.

The explanation for the slip given by the Department of the Environment (DoE) enquiry (Coxon, 1986) and by the Author, requires a reduction in the angle of friction to a residual value of about $12^{\circ}-14^{\circ}$ throughout the fill and valley sides, realized by a progressive failure initi- ated at the valley side (DoE) or centre (the Author) and then transferred laterally along the dam by shear. The pre-existing reduction is due to glacial action on the valley sides and to plant action on the fill.

The problem in accepting this explanation is that there are so many examples, previously referred to, that have not behaved in the same way. If the explanation is accepted, then these other existing embankments need careful reconsideration regarding their stability.

A further anomaly is that while residual $\phi$ values of $12^{\circ}-14^{\circ}$ may be achieved in some tests, these are lower bound values from a much wider spread of results, typically $14^{\circ}-20^{\circ}$, particularly in more cemented or sandy samples. In the field the pre-existing shear planes in the valley sides are interrupted or modulated by the irregular depth of residual weathering, with relics of the less susceptible materials projecting upwards. Within the fill, polished planes are formed by compaction but the mudstone blocks in the next fill layer puncture the smooth surface of the previous layer so that the effect is not a continuous smooth plane but one with some intermittent shear 'keys'.

Another anomaly is that the horizontal action and reaction of the core on to the upstream $\left(18^{\circ}\right)$ and downstream $\left(22^{\circ}\right)$ shoulders is roughly equal and opposite. After allowing for the effects of the boot in weakening the upstream shoulder, it is incompatible that the steeper downstream shoulder shows no sign of movement, while the low angle of friction common to both shoulders is held solely responsible for the movement of the upstream shoulder. In summary a large reduction in the angle of friction is not acceptable as a complete explanation because it would be almost unique to this site; some other factors must be involved.

Where other embankments have failed, a common element seems to be water. Shallow surface slips frequently occur where water collects in the more permeable voided zones at the bottom of a compacted layer, trapped by the impermeable surface of the next compacted layer.

Deep-seated failures (e.g. Aberfan) can occur when the shale fill is loose (voided) and saturated from below, as was the case at the base of Carsington where rising groundwater was trapped on the upstream side and probably inhibited compaction.

The structure of shale fill consists of an aggregate of partially cemented mudstone blocks, each with a high negative internal pore pressure, which when disturbed or crushed under water, soften and swell, absorbing external water. Surrounding the blocks are usually $5-15 \%$ macro voids which are the residue of air introduced by excavation and partially removed by compaction. When 
these macro voids are flooded the blocks soften at the points of contact and the aggregate structure around the macro voides collapses, raising the pore pressure in the voids and/or expelling water. Concurrently or consecutively the mudstone blocks swell absorbing the released macro void pore water. This behaviour can be demonstrated in large-scale oedometers where compacted mudstones can be flooded under load (Cox, 1979).

To determine the average pore pressure in a closed system it is necessary to know the suction characteristics of the mudstone concerned (after crushing). At Carsington the plastic limit was about $23 \%$ (representing a low negative pore pressure) and the fill moisture content was typically $12 \%$ to $20 \%$ representing a relatively high negative pore pressure.

As a typical example, consider an element of fill initially at $14 \%$ moisture content and containing $10 \%$ macro air voids which are flooded by rising groundwater. The surrounding mudstone block structure starts to soften and collapse, causing a temporary rise in the pore pressure in the macro voids. The blocks swell to absorb the moisture in the macro voids giving a final moisture content of $20 \%$, still with a negative pore pressure. The average pore pressure was therefore negative but consisted of two parts: a positive pressure in the macro voids which rose locally and intermittently during periods of collapse, and a simultaneous negative pore pressure within the micro voids of the blocks.

The piezometers at Carsington were placed in well compacted mudstone mid-way between the drainage layers (which were probably the source of the water causing collapse). It seems likely these would record an average (negative or low) pressure rather than high intermittent local values in the macro voids. Temporary pressures would probably only register on very stiff, rapidresponse, continuously recording piezometers placed in a void system. Gas pressures internally generated by the highly acidic fill against the limestone drains may also have locally raised void pore pressures. The gas pressures would also have gone undetected.

In terms of shear strength, two simultaneous pore pressures mean two effective stresses: a high one within the blocks and a low one in the aggregate. I would like to suggest that this temporary reduction in effective stress within the shoulder fill was the additional cause of failure at Carsington. The points which tend to confirm this are that, initially, water tended to accumulate at the base of the fill on the upstream side and would have been retained, making compaction difficult and possibly leaving more voids than normal. The shoulder fill when wetted could be expected to collapse and a net collapse was measured by net volume change, by settlement gauges, and by the effect on adjacent piezometers in the core. (The core piezometers showed a delayed rise in pore pressure, after loading and filling had ceased probably due to flooding of the lower downstream shoulder - followed by collapse settlement and downdrag of the shoulder on the core, thereby raising the core pore pressure. See Naylor, 1989).

The 'macro' pore pressures in the base of the upstream shoulder could be expected to rise temporarily after wetting or additional loading. At Carsington both these conditions occurred almost simultaneously (a minor earth tremor and exceptional rainfall) immediately preceding the final failure.

I believe the Author is correct in his analysis that the failure commenced near the centre. However, I suggest that a temporary pore pressure could be expected to occur locally and intermittently in the lower upstream shoulder (and not elsewhere) which would not necessarily be recorded by conventional piezometers. This would help to explain the failure without the need for exceptionally low $\phi$ values and which would otherwise dispute the safety and stability of a very large number of existing shale embankments.

\section{W. Isherwood, Edgar Morton and Partners}

It has been my experience that shears, where present, can be identified almost immediately following excavation of trial pits, etc. Moreover, my reading of the literature dealing with failures attributed to the presence of solifluction shears has led me to believe that such shears were quite readily identified by such means. At Carsington, the alleged solifluction shears only became apparent after long exposure of the sides of trenches during prolonged hot, dry weather, and certainly there were no traces of such features when the trial trenches in the virgin ground were first opened up. It would indeed complicate site investigation contracts and procedures in periglacial areas if all trial pits and trenches had to be left open for uncertain periods of time, possibly weeks, and hot-air blowers provided, so that any solifluction shears would become apparent.

Following on from the Author's explanation of the effects of shrinkage due to drying, it seems to me that what was occurring in the trenches at Carsington mirrored in the field the process by which detailed structure is identified in split, undisturbed samples left to partially dry out in the laboratory. If the features identified as solifluction shears at Carsington really did have such an origin there would be strong reasons for amendment or addition to BS 5930 to ensure that such features may not be missed in future. On the 
other hand, if the features at Carsington are acknowledged not to be solifluction shears, the official reports by Babtie Shaw \& Morton \& Skempton (1986) and Coxon (1986) will require some amendment.

It is interesting to note that the post-failure report by the British Geological Survey spoke only of their 'belief' that 'head' deposits form a blanket cover beneath the topsoil over the entire site, except the alluvial plain flanking the Scow Brook. They further stated that 'head' derived by solifluction has, 'by definition', moved relative to the underlying clayey mudstone along shear planes at or close to the boundary. They 'understood' that such planes were recognizable as relict shears in many sections across the site, but it would appear that they did not see them. Their professional opinion on the very undulating and discontinuous nature of the features and the possible process by which they were formed was never offered, nor apparently sought.

The British Geological Survey did, however, inspect several samples from trial bores sunk at the time, and while they identified material as 'head', no mention was made of the particular samples containing shear planes. Such was the evidence upon which they evidently relied when they commented that such planes 'appear' to have contributed to the slippage associated with the dam failure.

P. R. Vaughan, Imperial College of Science, Technology and Medicine, and R. W. Chalmers, Babtie, Shaw \& Morton, Glasgow

The Author concludes that the causes of the slip in the upstream slope of the Carsington embankment in 1984 were substantially different from those deduced from the technical investigation into the failure, which was commissioned by the owner and directed by Babtie Shaw \& Morton and Professor A. W. Skempton. We were associated with much of this investigation. The final results were presented to the owner in 1986 in an unpublished report (subsequently referred to as 'the report'). This report was reviewed by Coxon (1986) and its conclusions do not differ significantly from those published earlier (Skcmpton \& Coats, 1985; Skcmpton, 1985). Information obtained during the removal of the slide - not available to the Author-is compatible with that previously reported. A final report on these events is currently in preparation (Rocke, Skempton \& Vaughan, 1992).

The Author states that the report contained omissions and factual errors and offers alternative hypotheses to explain the slide. We attempt here to establish, compare and evaluate the alternative explanations. The Author does not quote the con- clusions of the report fully, and these will first be stated. To avoid confusion the large-scale movements starting on 4 June 1984 are described here as the collapse. Failure is used more generally to describe the full mobilization of strength locally. The Carsington Dam crosses two valleys. The slide took place where the embankment crosses the main valley. In what follows the north flank refers to the length on the north side of the main valley, represented by the section at chainage $725 \mathrm{~m}$, and the centre to the length across the centre of the valley, represented by the section at chainage $850 \mathrm{~m}$.

We believe that the following is common ground between the Author and the report. The collapse was first observed on the north flank of the valley and it subsequently spread across the valley to the south flank. The slip surface passed through the core and the core extension (the 'boot') and, on the valley sides, through a thin layer of in-situ clay on the surface of the foundation. In the centre of the valley, where the layer of clay was absent, the slip surface passed mainly through the base of the fill. Deep-seated sliding was the critical mode of failure at the end of construction because of the presence of the wide boot of weak, undrained clay fill with high excess construction pore pressures. All the materials through which the slide occurred were brittle with low residual strengths, and so could suffer significant strength loss when sheared.

\section{Further conclusions of the report}

The report concludes that the mechanism of failure developed on the north flank, where the embankment was being raised at the time and where collapse was first observed. The mechanism was not influenced by the behaviour of the embankment on either side, and therefore could be analysed in two dimensions without error. The factor of safety, according to conventional limit equilibrium analysis using the peak strengths of the intact soils measured during the site investigation, was significantly greater than unity. Therefore the failure could not be explained in simple terms and the causes of the discrepancy were examined. They were presented as proportionate reductions in the safety factor, determined using peak strength, to give a value of unity at collapse. The causes of the discrepancy and their significance were summarized as

(a) progressive failure due to the brittle nature of the soils involved, accentuated by the presence of the boot as a strain concentrator (a major effect);

(b) intermittent shears in the foundation clay due to periglacial soliffuction movements (a significant effect); and 
(c) shears in the core and boot fill due to rutting by construction plant (a minor effect).

The shears present reduced the bulk peak strengths along the slip to less than the intact strengths measured on small samples. Progressive failure reduced the average operational strength at collapse to less than the average peak bulk strength. The reduction of safety factor due to progressive failure was examined independently by finite element analyses developed for the purpose, and this was found to be sufficient to explain the collapse (Appendix 7 of the report and Potts, Dounias \& Vaughan, 1990).

The propagation of the collapse across the valley was attributed to lateral load transfer as successive 'slices' through the slide failed and tried to move to a new equilibrium position, aided by the low real safety factors in the valley centre and on the south flank. These, again, were lower than was indicated by limit equilibrium analysis based on peak strengths. The causes of this weakening were found to be progressive failure and shears in the core and boot, plus a minor effect due to horizontal construction surfaces in the mudstone fill through which the slip surface passed. The effect of progressive failure was again assessed by finite element analysis and was found to be sufficient to account for the failure. The effect of lateral load transfer was quantified approximately by a lumped parameter analysis and it was also found to be sufficient to explain the collapse (Appendix 8 of the report and Vaughan, 1985, 1991).

\section{Author's alternative hypotheses}

The arguments in the Paper are complicated and we consider it wise to summarize what we believe are the Author's conclusions before commenting on them.

The Author deduces that the failure process started not on the north flank, but in the valley centre. $\mathrm{He}$ asserts that the embankment here moved sufficiently during the 1983 placing season and early in 1984 to 'drag' the section on the north flank beyond its peak resistance by lateral load transfer. This section, temporarily not in equilibrium, then moved sufficiently for the load transfer to reverse, with the north flank section supported by the central section which had been reinforced by the construction of a small berm at the end of 1983. The north section finally collapsed due to the extra load as it was completed in 1984. The collapse then spread across the valley by lateral load transfer.

The Paper and the report agree that, at both the centre and the north flank the sections were nearer failure than was indicated by limit equi- librium analyses using measured peak intact strengths. The centre section might well have collapsed had it been raised to full height, and concern on-site in early 1984 about the magnitude of the movement at this section was wellfounded. The Author concludes that the reasons of this weakness were, at both sections, horizontal shear surfaces in the core and boot due to the effects of rolling, which had a greater effect on stability than the report allowed for shears due to rutting. At the valley centre the Author concludes that horizontal shear surfaces at near residual strength were also created by rolling the mudstone fill, and that their effect was much greater than that of construction surfaces allowed for in the report. On the north flank he considers that the shears in the foundation clay had no effect as they were not there. The observation of such shears in pits outside the slip he attributes to errors in the investigation. He invokes an equivalent weakening effect, partly due to the increased effect of shears in the core, but primarily due to the pre-collapse weakening by lateral load transfer described above. The Author's hypotheses allow collapse to be explained with little effect from progressive failure. They are now reviewed in more detail.

\section{Lateral load transfer from the centre to the north flank prior to collapse}

The possible influence of lateral load transfer prior to collapse was assessed in Appendix 9 of the report. It was found that sufficient load transfer from the centre to the flank prior to collapse to weaken the flank section was very improbable. The following factors are pertinent.

(a) At the time when the centre was moving more than the north flank and could have been transferring load towards it, the safety factor on the north flank (by an analysis scaled to give a value of unity at collapse) was more than $1 \cdot 2$, due to the lower height of the section at this time. Thus a $20 \%$ increase in disturbing force was required to drag the section to peak resistance, only after which could it be weakened towards residual resistance by further displacement.

(b) Over this pcriod the measured differential horizontal movement at the toe was no more than $100 \mathrm{~mm}$, and the average relative movement between the toe and the core could have been no more than twice that. The longitudinal strains available during collapse to promote lateral load transfer were estimated to be at least 50 times greater than those available prior to collapse. Therefore an influence during collapse did not imply an equivalent influence before collapse. 
(c) The Author's postulate requires that this small relative movement, over a distance of more than $100 \mathrm{~m}$, was sufficient, first to allow the north flank to be dragged to failure and weakened by further displacement, and second for it to move sufficiently, relative to the centre, for the load transfer to be reversed and for the flank to be supported by the centre. When analysed, this requires a high and improbable lateral stiffness.

(d) The analysis of lateral load transfer showed that if a slide started which had a width normal to its direction of movement of more than twice its depth, it could develop sufficient out-of-balance force either to continue by propagation laterally by lateral load transfer, or to form end shears and fail as a block. A length longer than this could not be supported by lateral load transfer without collapse. Therefore a weakened section on the flank more than about $40 \mathrm{~m}$ long could not have been supported by the centre.

In the report, the initial collapse was explaincd by the presence of shears plus progressive failure, with no lateral load transfer prior to collapse. The weakness of the centre section was therefore not the cause of collapse. The presence of lateral load transfer prior to collapse is central to the Author's argument that the process leading to collapse started in the valley centre.

\section{Pre-existing discontinuities in the fill due to construction}

There are three types of discontinuity to be considered. The first type is rutting shears, which are formed where bearing capacity failure occurs under the wheels of construction plant. They are inclined at various angles and are weakened towards residual strength by shearing. The second type is horizontal compaction shears. These are formed on the interface below the layer bcing compacted, due to relative movement between the two layers as the upper layer is rolled (White \& Vakalis, 1983, 1985, 1987). They are weakened towards residual strength by shearing. The third type is horizontal unsheared compaction surfaces. They arise through the burial of surfaces smoothed by placement and compaction. Strength loss is likely to be less than in the first two types of discontinuity. Scarification of compacted surfaces prior to placing a new layer was specified to reduce the effect of such surfaces.

\section{Weakening due to shears in the core and boot}

Rutting shears were observed in the core during the investigation and their creation was demonstrated by field trials. They were observed in the core and boot when the slip was excavated.
Allowance was made for their presence in the bulk strength adopted in the report, on the assumption that their orientation was random. The Author postulates the presence of horizontal compaction shears and deduces that such shears could have caused a greater loss of strength in the boot than the random shears considered in the report, although conversely, as noted by the Author, they would have had little effect within the core where the slip surface dips steeply. The effect of either type of shear on stability is relatively small.

No horizontal compaction shears were observed in the core and boot, either within the slide or outside it, during the investigation of the slip or during the subsequent removal of the old core. None have been observed during the construction of the new core of similar but slightly stronger fill. It seems that the action of plant in this particular case is dominated by rutting. White \& Vakalis (1987) conclude that this may be so in weak fills.

\section{Shears in the mudstone fill at the valley centre}

The Author postulates that horizontal compaction shears at near residual strength were formed in the base of the mudstone fill at the valley centre where failure occurred. This was promoted by wetting up of the fill due to rain. He states that these shears were the major cause of weakening and thus of the movements which occurred at the centre section prior to collapse. Thus, in the Author's sequence of interacting effects, their presence caused the collapse on the north flank.

Horizontal sheared surfaces were found in the base of the fill where the failure had passed through it, both during the post-collapse investigation and during removal of the slip. Those exposed during the removal of the slip showed striations in the direction of the slip. Occasional matt and unsheared surfaces of limited extent were found in the fill of the old embankment and have been found in the fill of the new one. These were probably due to the burial of surfaces on which a layer of remoulded clay had been formed by traffic, and which had escaped scarification. One sheared surface was found at ch. 620 in the mudstone fill just above the foundation clay layer, which also contained continuous shear surfaces matching the slip. The shear in the fill had striations in the direction of slope movement. It is believed that the first layer placed on the foundation may not have been scarified to avoid the risk of damage to the drainage layer beneath. The occurrence of shear surfaces in both the fill and the foundation below suggested that horizontal surfaces in the fill may have had a peak strength only a little greater than the foundation clay. The 
report concludes that the continuous sheared surfaces in the fill had formed due to the slip, although possibly on surfaces between layers which were weakened. A small reduction in peak strength was considered sufficient to allow for this. Thus there is agreement with the Author that there was weakening, but disagreement over its magnitude and, in particular, over whether or not there were pre-existing horizontal sheared surfaces at near residual strength.

It is impossible to prove what existed prior to the slip. However, the following circumstantial evidence must be considered.

(a) As noted by the Author, although numerous trenches were dug to install instrumentation, no sheared surfaces were noticed in the fill during construction. The Author concludes this was because they were buried and difficult to see and not because they were not there.

(b) No continuous sheared surfaces have been found in mudstone fill except where the slip could have caused them. No such surfaces were found in the fill at the base of the embankment on the downstream side or, except in the one instance described above, in the upstream fill where this was above the foundation clay layer in which the slip had occurred, even where this fill was at the same level as the sheared surfaces found in the valley centre. No sheared surfaces have been found in the mudstone fill of the new dam, which has been much more heavily rolled than the fill of the first embankment. Therefore the Author's hypothesis requires that special conditions capable of promoting sheared surfaces existed only during placement of the base of the upstream fill in the valley centre.

(c) There is no evidence that the fill at the base of the upstream shoulder was significantly different from that elsewhere, except that it was saturated by groundwater impounded in the base drain layer upstream of the core. Piezometer records show that this water level rose more slowly than the fill, and that the fill was not generally influenced as it was placed or compacted.

(d) Fill had been placed at the north end of the dam for nearly a month before placing started in the valley centre, so the borrow pit should have been well developed with typical fill coming from the appropriate levels.

(e) White \& Vakalis (1983, 1985, 1987) indicate that polished and sheared surfaces are only generated by compaction in fills wet of optimum. Judged from compaction tests performed during the reconstruction and the water contents measured above the water table during the investigation, the Type II mudstone fill through which sliding occurred was usually placed dry of optimum. A water content equivalent to the threshold value reported by White \& Vakalis would have required the addition of more than $3 \%$ water by weight-more than $60 \mathrm{~mm}$ of water per metre thickness of fill placed. This is more than the rainfall quoted by the Author.

( $f$ ) It is not necessary to invoke sheared surfaces to explain the collapse.

Although no proof is possible, the circumstantial evidence does not support the presence of continuous sheared surfaces in the fill prior to collapse, although some weakening on horizontal construction surfaces is probable.

\section{Shears in the foundation clay layer on the north flank}

On the flank the slide took place in the clay layer in the top of the foundation, and the presence of pre-existing discontinuous shear surfaces in this layer is postulated in the report. This could not be proved by post-collapse investigation, since the shears would have been incorporated in the slip surface. The circumstantial evidence for their presence was, first, that they could be expcctcd on such slopes from precedents well established in Quaternary geology, and, second, that they were found in trial pits outside the dam in slopes similar to those on which the dam sat. Discontinuous surfaces cannot be caused by the main downslope movement of the head material during solifluction and at Carsington, as elsewhere, they occur just below the head rather than at the interface. They seem to be due to local movements induced by freezing and thawing.

The Author states that such shears were not present. He ignores precedent and concludes that the shears observed outside the dam were formed by shrinkage after the trial trenches in which they were observed were opened. In support of this view, the Author states that they were not discovered until some time after the pits were opened. This is only partly true. It is well known that it is difficult to find such surfaces in soft clay, as the clay cannot be split easily on the shear surface to show evidence of shear which could not be due to the process of splitting. The clay becomes easier to separate as it dries, but discovery of shear surfaces is never automatic unless cracking actually develops along the surface Because of these difficulties, Professor Chandler was asked to examine the head material at Carsington and to look for shears. The work outside the dam foundation was not a first priority and 
Professor Chandler did not visit the site until around seven weeks after the investigations had been commissioned. At this time several trial pits upstream of the dam had been opened for some weeks. Two additional pits were opened for Professor Chandler's visit. He examined five pits and found shears in four, including one of those freshly opened. Thereafter, shears were found in further trial pits immediately after they were dug, although detailed logging was left until some drying had made it easier.

The shears found did not show evidence of differential movement after the pits were opened, they did not have the form of shrinkage cracks, and they were often gleyed (the report, section 6; Skempton, Norbury, Petley \& Spink, 1989), indicating their relatively ancient origin. Similar shear surfaces have been found under the dam, as it was removed, outside the area of the slide, and without a delay which would have allowed shrinkage. All this evidence indicates that the shears found outside the slide were not caused by shrinkage. It remains very probable, therefore, that they were present in the foundation where the collapse started.

\section{Conclusion}

The 1986 report concludes, on the balance of evidence, that the process leading to collapse started on the flank wherc the initial collapse was observed. Collapse was not explained by conventional analysis using the peak strengths of the intact materials. Collapse is explained by weakening due to pre-existing sheared surfaces in the fill and in the foundation clay, and by a degree of progressive failure which is recovered by an independent finite element analysis. The two effects were approximately equal. The collapse then spread across the valley centre, where the real factor of safety was low but greater than unity, by lateral load transfer.

The Paper offers an alternative and more complicated mechanism involving pre-collapse weakening of the section on the north flank due to load transfer from the valley centre. This allows the Author to explain the initial collapse without weakening due to sheared discontinuities in the foundation and with less progressive failure than was invoked in the report. In contrast, in the valley centre, he says that weakening was due to pre-existing horizontal sheared compaction surfaces and that this was so severe that little progressive failure occurred.

We consider that the hypothesis of pre-collapse weakening of the flank by the centre cannot be justified by either judgement or analysis. 'lhus the weakness in the valley centre did not cause the collapse on the flank, which was an independent event. The presence or absence of extensive pre- existing horizontal sheared surfaces in the fill in which failure occurred in the valley center cannot be proved by direct observation. The balance of evidence indicates that they were not there, although some weakening on construction surfaces is probable. The presence of shears in the foundation clay layer, again, cannot be proved by direct observation. The balance of evidence indicates that they were there. The shear surfaces observed in similar ground outside the slide were not formed by shrinkage after the trial pits were opened.

The Author is right to stress the potential destabilizing effects of sheared discontinuities formed by construction in plastic clay fills, although their role at Carsington seems to have been relatively minor. $\mathrm{He}$ is wrong to deny similar effects due to naturally occurring sheared discontinuities. We consider that a significant effect from progressive failure at Carsington is proven beyond reasonable doubt. The assumptions and arguments of the Author cannot be substituted for it. We consider that the conclusions of the 1986 report remain valid.

\section{Author's reply}

Karl Terzaghi set a high standard of discussion on my first publication in the Proceedings of the Institution of Civil Engineers by stating first what he recognized to be new and right before enlarging on detail. That was equivalent to marking the control points of a survey, placing comments in perspective. It is significant that Dr Penmanwho has published some of the Carsington material in his Rankine Lecture and given a great deal of thought as to the causative mechanismshould not only have grasped the essence of Figs 16-18 of my Paper at the start of the spread of progressive failure from the centre, and said so at the outset, but should even have extended the correlations in Fig. 27. Whereas the vital load transfer from an early stage was first published by the Author in 1986, this inherent feature of any slip mechanism has not been widely recognized. It is sometimes more difficult to pick out the needle from the haystack than to describe the needle. $\mathrm{Mr}$ $\mathrm{Knight}$ has also identified the causative mechanism in the light of his own extensive experience, and Dr Cox comes finally to accept that failure commenced in the centre. Mr Isherwood has understood the mechanism since 1985. Their welcome published statements mirror the response to invited lectures I gave between 1986 and 1992 and a considerable volume of private communications.

Whereas it may be disappointing that Professor Vaughan and $\mathrm{Mr}$ Chalmers omitted to 
address the records of field performance, their reference to previous publications was welcome.

The pertinent points raised by Dr Penman regarding aspects of design and monitoring of the embankment remain of interest, but he may appreciate that these subjects not only lie beyond the subject matter of the invited Paper but also require a prior accepted understanding as to true causation before lessons can be learned properly with hindsight. It is strictly essential to analyse the construction events and the site correspondence, to have witnessed verbal discussions and, as $\mathrm{Mr}$ Coxon noted, to appreciate how decisionmaking was structured before one can understand the relation between measurements and subsequent events. To this end I have been conducting research partially in parallel with that for the Paper, and it is believed that the findings might ultimately have some historical value.

Notwithstanding the delightful witticism of $\mathrm{Mr}$ Knight, presumably he did not miss the point. It was a central purpose of the Paper that in time 'the profession' (namely designers, constructors and inspectors of earthworks) should all have sufficient knowledge of the dangers of what otherwise might be regarded merely as occasional rutting. In contrast to Knight (1989a), in his discussion on Carsington (Knight, 1989b) he did not apply his knowledge to challenge the then current mechanism. This is no criticism, for $\mathrm{Mr}$ Knight did not have before him the field observations I have since collected; it simply highlights yet again the difficult difference between foresight and hindsight.

In contrast to Dr Penman's recognition of the direct relevance of the boot, Dr Cox in his first, second, fourth and final paragraphs appears to me to miss it altogether. It may well be that some of the successful coreless and bootless shale embankments did (and do) have plant shears in them which alone did not lead to failure. The use of the smooth-wheeled roller is relatively common. But his conjecture re shear keys should take account of the independent evidence of Soil Mechanics Ltd, reproduced in Fig. 8.

It is not true that the downstream shoulder showed no signs of movement. Nor did I presume to present a complete explanation based solely on plant shears. Twelve main sets of evidence were presented and correlated. Only when all or most pieces of a jig-saw puzzle are set in their correct relative positions can the final picture be seen. Further pieces of evidence are given by Rowe $(1985,1986)$ and I am indebted to Dr Cox for the benefit of his correspondence at that time, and for his observation here that "initially water tended to accumulate at the base of the fill on the upstream side'. This is one reason for a difference between the state of the fill upstream and downstrcam of the cut-off when working $5 \mathrm{~m}$ below equilibrium groundwater level without deep dewatering. Another relates to daily events in the borrow pit. I accept that the mechanisms which Dr Cox describes relating to limited but possibly critical rising of water up into the mudstone fill overnight at the start of the main embanking, 27-28 July 1982 , are consistent with the basal part of the independent findings in the shaft at ch. 825 , but the Naylor (1989) load transfer from shoulder to core is the reverse of Figs 17 and 18 in the Paper.

When Skempton \& Coats (1985) presented their paper on the mechanism of failure they stated that, as on 4 June at the time of 'failure', a factor of safety of 1.35 applied over the central section of the embankment and that 'there is little doubt that to achieve a factor of safety of 1.0 an appreciable transfer of load is required from the initial slip further north'. They added: 'Dr Vaughan is investigating this problem; he finds that the load transfer can reduce the factor of safety at ch. 850 by 30 percent, based on reasonable, not in any way extreme, assumptions'. At this, an involuntary gasp arose from the audience. Vaughan (1985) indicated how failure could even have been propagated had the factor of safety at the centre been $50 \%$ above unity. That came about by taking the residual resistance on the base of successive slices, and reliance on the existence of high boundary forces at high shear strains. I used $6.9 \%$ drag effect on the factor of safety, Table 8 ; only $14 \%$ of Vaughan's failure value. Stress-strain curves for soils, especially in boundary shear, are highly non-linear. The strain at $14 \%$ maximum is only a few per cent of the strain to failure. This can be seen, for example, in Fig. 7 of Potts, Dounias \& Vaughan (1990), and one might expect compacted mudstone to be stiffer. Thus the pleading of a factor of 50 between strain during collapse and that available prior to collapse is not in contradiction with a modest but significant contribution by side drag up to 21 May.

The north flank was not lower on 21 May (see Fig. 7(b)); a $20 \%$ factor was not necessary (see Table 8 ); and a previously missed factor of at least $14 \%$ arises from $\pm 7 \%$. Soils are five to ten times stiffer on initial reversal of stress, this being a feature of the sensitive relation between boundary movements and shear stress in retaining structures of all types. That is why the failure process from 21 May, after which the movement was unstoppable, took two weeks to develop rather than under an hour as might otherwise be expected. This time effect from 21 May is one of the many points which the contributors have not addressed.

In the light of all the evidence, I wonder if the contributors imagine that had the north side been 
strengthened with a berm, or had no berm been placed at the centre, that no failure would have occurred at the centre? Once they can join all those that can see all the evidence of progression to failure at the centre since 1982-1983 entirely through fill, they may see that they are pleading that the embankment suffered two quite separate major sources of weakness. Moreover, one cannot neglect the effect of the partial berm which delayed failure at the centre without arresting the advance of the central section relative to the sides.

The further reports of the distribution and type of plant shear amount to the following. In Fig. 20 there is little difference between the final, separate, estimates of remaining safety at the agreed weakened ch. 850. That section finished on the verge of failure and finally did so for the reasons given in Fig. 23. It did not need a longitudinal load transfer of $30 \%$ or $50 \%$. The exact percentage and distribution and types of plant shear in the mudstone may never be known. If in the boot no extended plant shears were found, and if in fact Soil Mechanics Ltd have proved they were not there, then early integration of the profuse rutting shears from 1982-1983 would be sufficient to explain the lateral load transfer described in Figs. 16-18. The agreed existence of weakness is consistent with the abnormally early redistribution of internal pressure when the bank was flat.

Under Professor Vaughan's and Mr Chalmers' 'circumstantial evidence', (b) appears to neglect the findings of Soil Mechanics Ltd (Fig. 8). Moreover the downstream shoulder at the centre was raised in August and the groundwater levels downstream of the cut-off were lower. It is entirely misleading to cite the absence of shears in the new dam without explaining the prior deep dewatering. Item (c) appears to acknowledge, for the first time, Rowe $(1985,1986)$, consistent with the conditions addressed by Dr Cox. In item $(d)$ the prior fill placed 'at the north end' refers to a separate valley, St. A, won from faces developed earlier from other areas and levels. The pit as a whole was not 'well developed'; rather, on 27-28 July 1982, a face (contrary to original specification) was being worked between a $6 \mathrm{~m}$ bench and $2.4 \mathrm{~m}$ depth. By 29 July this source of fill led to material on record as being rejected and reclassified as B2'. The records of the material actually found to have been placed are stated on p. 405 of the Paper. Rather than speculate on what should have happened, it is essential to examine what did happen. In item (e) it is agreed that plant shears arise with fill wet of optimum. It is wholly misleading to suggest that the rise of water level could not exceed that of the average rainfall. The works were below groundwater level, fed from the valley sides into the ground blanket, with a single pump located above the outlet end of the blanket. Was the later $5 \mathrm{~m}$ water rise due only to rainfall?

The reference to "precedents well established in Quaternary geology' might be read in conjunction with Mr Isherwood's statements relating to the British Geological Survey. Moreover, we are led to imagine that freezing and thawing over the whole valley at a given depth was selective to spots a short distance apart. There are many unanswered questions relating to the varying relative locations of head and boulder clay. Without precedence one cannot necessarily work forward from complex geological formations to how the mass behaves under engineering stress change. Knowledge has been built by the reverse path first. Potts et al. (1990) stated that 'There has been no specific case-history from which the effect of progressive failure can be deduced unambiguously'. They applied the progressive mechanism not just to the long known region peak to critical state, but also between critical state and the residual. If such precedents were so well established in Quaternary geology why did not Professor Skempton highlight them and address intermediate states between critical state and the residual in his publications 1964-1984?

The lynch pin of the investigators' approach in 1984 consisted of an $F=1$ back analysis of the north side as at 4 June. That method had not changed from that published in the discussion of the failure of the Hollowell embankment (McClellan, 1944). The search was on to explain why the average angle of shearing resistance to fit back analysis lay midway between critical state and the residual on the 4 June. The direct field evidence in the Paper that soil failure displacements commenced on 21 May, leading inevitably to post-failure progression towards the residual strength of the clay foundation on the north side before 4 June, has been totally disregarded by the contributors. Instead, they adhere to the steps (a) assumption of pre-construction weakness at ch. $705,(b)$ back analysis, (c) ergo a new principle in soil mechanics that $\phi^{\prime}$ can lie anywhere between peak and residual. The silence from the profession on this point has been deafening.

During the period 1984-1990 Professor Vaughan (or his senior colleagues) revealed a necessity to introduce a series of modifications to the details of analytical post-fit, tending to reduce the proportion of initial 'pre-existing' shears to suit their improved analysis (see Table 9). Following an interim report, a paper, a 'final' report of nine volumes, and material published in Géolechnique which did not result in any published discussion, one can appreciate that Professor Vaughan and $\mathrm{Mr}$ Chalmers chose to address their present position rather than to 
respond to the new evidence. But it may be difficult for the reader to comprehend how, in their conclusion, they can plead that my step-by-step diagnosis and correlation of events can lead to a 'more complicated mechanism' than that of the galaxy of parameters in the nine volumes of the report. On the balance of evidence a single sequence of interconnected events within the confines of established soil mechanics has to be more compelling than reliance on the incidence of two independent sources of weakness and failure, one without precedence.

\section{REFERENCES}

Babtie, Shaw \& Morton \& Skempton, A. W. (1986). Carsington Dam: investigation of embankment. The mechanism of failure. Report to Severn Trent Water Authority.

Cox, D. W. (1979). Volume change of compacted clay fill. Clay fills, pp. 79-86 London: Institution of Civil Engineers.

Coxon, R. E. (1986). Failure of Carsington Embankment. Report to Secretary of State for the Environment. Department of the Environment, London.

Knight, D. J. (1989a). Construction techniques and control. Clay barriers for embankment dams, pp. 73-86. London: Thomas Telford.

Knight, D. J. (1989b). Discussion on Carsington Dam. Clay barriers for embankment dams, pp. 156-162. London: Thomas Telford.

McClellan, A. G. (1944). The Hollowell Reservoir Scheme for Northampton. Discussion by A. W. Skempton. Trans. Inst. Water Engrs 49, 204-208.

Naylor, D. J. (1989). Discussion on Carsington Dam. Clay barriers for embankment dams, pp. 169-171. London: Thomas Telford.

Parsons, A. W. (1978). General report: Construction and placement of clay fills. Clay fills, p. 311. London: Institution of Civil Engineers.
Parsons, A. W. \& Perry, J. (1985). Slope stability problems in ageing highway earthworks. Failures in earthworks, pp. 63-78. London: Thomas Telford.

Pavlakis, G. (1978). Discussion on Construction, placement and methods of treatment of clay fills. Clay fills, pp. 266-269. London: Institution of Civil Engineers.

Potts, D. M., Dounias, G. T. \& Vaughan, P. R. (1990). Finite element analysis of progressive failure of Carsington embankment. Géotechnique 40, No. 1, 79 101.

Rocke, G., Skempton, A. W. \& Vaughan, P. R. (1992). The failure of Carsington Dam. Submitted for publication.

Skempton, A. W. (1985). Geotechnical aspects of the Carsington Dam failure. Proc. 11th Int. Conf. Soil Mech., San Francisco, vol. 5, pp. 2581-2591.

Skempton, A. W. \& Coats, D. J. (1985). Carsington Dam failure. Failures in earthworks. pp. 203-220. London: Thomas Telford.

Skempton, A. W., Norbury, D., Petley, D. J. \& Spink, T. W. (1989). Solifluction shears at Carsington, Derbyshire. 25th Annual Conf., Engng Group, Geol. Soc. Lond. pp. 277-285.

Vaughan, P. R. (1985). Discussion: questions raised by the Carsington Dam slide. Influence of random discontinuities on shear strength and lateral load transfer. Proc. 1/th Int. Conf. Soil Mech., San Francisco, vol. 5 , pp. $2817-2818$.

Vaughan, P. R. (1991). Stability analysis of deep slides in brittle soil-lessons from Carsington. Slope stability engineering, pp. 1-11. London: Thomas Telford.

White, I. L. \& Vakalis, I. G. (1983). An investigation into the development of polished interfaces in clay fills. Proc. 8th European Conf. Soil Mech., Helsinki, vol. 1, pp. 323-326.

White, I. L. \& Vakalis, I. G. (1985). Smooth slip surfaces in clay fills resulting from soil-machine interaction. Failures in earthworks, pp. 445-447. London: Thomas Telford.

White, 1. L. \& Vakalis, I. G. (1987). Shear surfaces induced in clay fills by compaction plant. Compaction technology, pp. 125-137. London: Thomas Telford. 